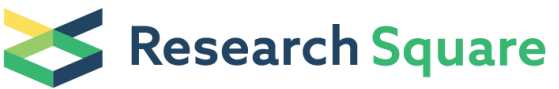 \\ Preprints are preliminary reports that have not undergone peer review. \\ They should not be considered conclusive, used to inform clinical practice, or referenced by the media as validated information.
}

\section{Non-sustainable of no-till agriculture for soil carbon storage increase}

\section{Andong Cai}

CAAS

\section{Tianfu Han}

Institute of Agricultural Resources and Regional Planning, Chinese Academy of Agricultural Sciences

\section{Tianjing Ren}

Institute of Environment and Sustainable Development in Agriculture, Chinese Academy of Agricultural

Sciences, Beijing 100081, P.R. China

\section{Jonathan Sanderman}

Woodwell Climate Research Center

\section{Yichao Rui}

Rodale Institute

\section{Bin Wang}

Institute of Environment and Sustainable Development in Agriculture

\section{Pete Smith}

University of Aberdeen https://orcid.org/0000-0002-3784-1124

\section{minggang $X u$}

National Engineering Laboratory for Improving Quality of Arable Land, Institute of Agricultural

Resources and Regional Planning, Chinese Academy of Agricultural Sciences

\section{Yue Li ( $\nabla$ liyue@caas.cn )}

Institute of Environment and Sustainable Development for Agriculture, Chinese Academy of Agricultural

Sciences

\section{Brief Communication}

\section{Keywords:}

Posted Date: January 25th, 2022

DOI: https://doi.org/10.21203/rs.3.rs-1271386/v1

License: (c) (1) This work is licensed under a Creative Commons Attribution 4.0 International License. Read Full License 


\section{Abstract}

Improved management of agricultural soils plays a critical role in mitigating climate change and achieving the Agricultural Sustainable Development Goals.. We studied the temporal effects of the adoption of no-tillage (NT) management, often touted as an important carbon sequestration strategy, on soil organic carbon (SOC) storage in surface and subsurface soil layers by performing a meta-analysis of 1061 pairs of published experimental data comparing NT and conventional tillage (CT). In the early years of adoption, NT increased surface $(0-10 \mathrm{~cm})$ SOC storage compared to CT but reduced it in deeper layers leading to a decrease of SOC in the entire soil profile. These NT-driven SOC losses diminished over time and the net change was approaching zero at 14 years. Our findings demonstrate that NT is not a "silver bullet" for drawing down atmospheric $\mathrm{CO}_{2}$ and regenerating the lost $\mathrm{SOC}$ in cropping soils globally and highlight the importance of long-term NT for the recovery of initial SOC losses.

\section{Full Text}

Mitigating global greenhouse gas (GHG) emissions and climate change is a grand challenge to mankind ${ }^{1}$. Agriculture is the second-largest source of GHGs with annual greenhouse gas emissions of 9.3 $\mathrm{Gt} \mathrm{CO}_{2}$ equivalent ${ }^{2}$. The historical carbon (C) loss from global cropping soils has not only contributed to increased GHG emissions and ongoing climate change but also threatened long-term food production and worsened water quality, biodiversity, and many other ecosystem services ${ }^{3,4}$. Whether agricultural technological innovations and conservation-based management shifts can reverse this trend remains highly uncertain.

No-tillage (NT) farming is a major agricultural development in the last few decades and has been widely promoted as a universal soil health principle ${ }^{5}$. Mainly achieved by technological innovations such as NT planters and a combination of genetically-modified seeds and agrochemicals, NT can potentially save costs, reduce fossil fuel consumption, soil erosion, and other negative impacts on soil health caused by tillage practices, and slow soil C turnover ${ }^{6}$. Despite numerous studies that have reported SOC sequestration achieved by NT, whether it is a reliable SOC sequestration strategy globally, in the long run, remains highly contentious ${ }^{7,8}$.

Accurate assessment of SOC sequestration under NT requires long-term monitoring of SOC changes of the entire soil profile, rather than merely the surface layers, where most existing research has focused on and increases in SOC storage were usually reported ${ }^{7}$. Studies that explored deeper soil layers, despite the scarcity of numbers, often indicate an opposite trend. The reasons for the vertical discrepancies are unclear, but may be due to the absence of mixing topsoil layers which receive most of the carbon inputs to the soil with deeper, soil carbon depleted layers, which usually occurs in tilled soils. This points to a great uncertainty of the actual SOC sequestration potential by NT. In addition, despite the highly variable duration of NT vs. CT comparisons in existing literature, spanning from 1 to 50 years, a comprehensive 
analysis of the temporal patterns of SOC changes under NT in the entire soil profile is lacking, limiting our ability to inform current policies regarding climate change mitigation.

Here we conducted a meta-analysis, drawing data from published studies around the world that investigated SOC sequestration under NT vs. CT (1061 paired comparisons from 144 studies). We assessed the time series of relative changes of SOC sequestration (NT vs. CT) of individual layers and the entire soil profile. We found that NT increased SOC storage at the soil surface $\left(0-10 \mathrm{~cm}, 3.47 \mathrm{Mg} \mathrm{ha}{ }^{-1}\right)$ relative to $\mathrm{CT}$ but reduced it in deeper soil layers $\left(10-60 \mathrm{~cm}\right.$, ) ranging from -0.28 to $-2.29 \mathrm{Mg} \mathrm{ha}^{-1}$, resulting in slightly reduced total SOC storage in the entire soil profile $\left(-0.24 \mathrm{Mg} \mathrm{ha}^{-1}\right)$ compared with CT (Figure 1). No difference in SOC storage was found between NT and CT below $60 \mathrm{~cm}$. These results suggested that both positive and negative benefits of NT on SOC storage should be considered simultaneously to properly assess the soil carbon sequestration effect of NT (Supplementary Figure 4). Critically, the relative SOC increases in the surface soil and decreases at depth under NT relative to CT diminished over time (Figure 2 and 3), indicating that NT-driven SOC changes diminished over time. As a result, the net SOC sequestration of the $0-60 \mathrm{~cm}$ soil profile was approaching zero when the experimental duration was 14 years (Figure 3).

These results clearly demonstrate that SOC sequestration under NT was limited to the surface soil and was only visible in the early years of adoption. When deeper soil layers were accounted for, NT led to decreases in SOC storage in the entire soil profile compared with $\mathrm{CT}$, although these decreases were alleviated over time (Figure 2). After 14 years, the variations of entire soil profile SOC changes under NT stayed in a narrow range $\left(0 \mathrm{Mg} \mathrm{ha}^{-1}\right.$ to $\left.1.07 \mathrm{Mg} \mathrm{ha}^{-1}\right)$. These results suggest that long-term effects of NT on SOC sequestration may not be significant and sequestration estimates based on surface soil data only, such as IPCC emission factors and output from widely used agro-ecosystem carbon models such as Daycent and DNDC, usually only accounting for 0 to 15 or $20 \mathrm{~cm}$ depth, are misleading 9,10 .

SOC storage is regulated interactively by plant $C$ inputs, soil microbial activity, and soil mineral matrix, with climate exerting first-order controls on biological activity. Although the underlying mechanisms of SOC dynamics under NT are inherently complex, a combination of changes in physical (e.g. aggregation, porosity, and structure), chemical (e.g., water and thermal condition and nutrients), and biological (e.g. soil fauna and microorganisms activity and diversity) related kinetic processes may have contributed to the observed patterns ${ }^{11,12}$. Increases in SOC storage at the surface and decreases at depth following the adoption of NT were not necessarily surprising, due to slower incorporation of crop residue into the deeper soil layers under $\mathrm{NT}^{13}$. The possible increased soil compaction and stratification due to NT may limit root growth and the amount of plant $\mathrm{C}$ inputs into deeper soil layers ${ }^{14}$. SOC storage of soil layers > $60 \mathrm{~cm}$ was not significantly affected by tillage treatments since this is below the plough layer. The SOC changes at $0-10$ and $10-60 \mathrm{~cm}$ soil layers, however, regulated by the above-mentioned processes, will eventually reach a new equilibrium controlled by climate and edaphic conditions. This is supported by the fact that mean annual precipitation, together with initial SOC concentration, were the most influential variables on the effect of NT on SOC storage among eight selected variables (Supplementary Figure 5). 
Higher mean annual precipitation and lower initial SOC concentration were more beneficial for SOC sequestration under NT compared with CT (Supplementary Figure $5 a$ and b), suggesting potential targeted areas where NT can lead to best outcomes of SOC sequestration at regional scales ${ }^{15}$.

Our analysis provides strong evidence that NT has limited benefits in atmospheric $\mathrm{CO}_{2}$ drawdown and SOC sequestration. While the adoption of NT has important soil health and agronomic benefits, including reducing soil erosion and runoff, improving soil structure and water retention, and reducing fuel and labor costs, NT alone should not be promoted as a panacea for climate change mitigation ${ }^{6,16}$. Future research should focus on unraveling: (1) mechanisms of SOC changes of different depths under NT over time, (2) how to increase the deep SOC storage under NT, (3) effects of long-term NT on SOC composition and function and crop productivity, and (4) hotspots and target areas where NT would achieve best outcomes in $S O C$ sequestration ${ }^{13,17}$.

\section{Methods}

Data sources. We obtained paired experimental data comparing NT and CT from peer-reviewed research literature through four academic websites, namely Web of Science (http://apps.webofknowledge.com), Scopus (https://www.scopus.com), Google Scholar (https://scholar.google.com), and China Knowledge Resource Integrated Database (http://www.cnki.net). We chose published studies that reported SOC changes of different layers in cropping soils. Combinations of "agriculture", "no-tillage", "zero tillage", and "soil organic carbon") were used as keywords in our search. We followed these criteria during data selection: (1) NT and CT were implemented simultaneously at the same site, and the experimental duration, SOC storage or concentration, and the depth of each soil layer should be clearly reported; and (2) management regimes other than tillage practices (e.g., cropping system, crop residues, and fertilization) should be identical, to exclude other confounding factors. The deadline for research literature was May 2021. The detailed process of reference selection is shown in Supplementary Figure 1.

Data preconditioning. To accurately assess the effect of NT on SOC change, we first distinguish SOC concentration versus storage. For soil organic matter reported in the target literature, SOC concentration was obtained by the following equation: SOC = soil organic matter/1.724. In many studies, only SOC concentration was reported and expressed as $\mathrm{g} \mathrm{kg}^{-1}$. The SOC concentration was then transformed into SOC storage (expressed as $\mathrm{Mg} \mathrm{C} \mathrm{ha}^{-1}$ for defined layers) by using the following equation:

\section{SOC storage $=\mathrm{SOC}$ concentration $\times \mathrm{BD} \times \mathrm{D} \times 10$}

where SOC storage and concentration were expressed as $\mathrm{Mg} \mathrm{C} \mathrm{ha}^{-1}$ and $\mathrm{g} \mathrm{kg}^{-1}$, respectively. BD is soil bulk density $\left(\mathrm{kg} \mathrm{m}^{-3}\right)$. $\mathrm{D}$ is specific soil layers depth (meter). The advantage of this approach is that it takes full account of changes in soil BD since soil BD is simultaneously affected by NT. 
To quantify SOC storage changes in each soil layer, we classified all soil layers according to a $10 \mathrm{~cm}$ gradient (e.g., 0-10 cm and 10-20 cm). If soil layers' depth spanned two or more gradients, this data was not considered in our next analysis. Where SOC storage studies were reported based on different depths (e.g., $5 \mathrm{~cm}$ or $8 \mathrm{~cm}$ ), the final data of SOC storage were obtained by multiplying a coefficient of 10/X.X was the depth (e.g., $5 \mathrm{~cm}$ or $8 \mathrm{~cm}$ ) of a specific soil layer. Overall, the 1061 pairs of experimental data from 144 studies were obtained (Supplementary Figure 2) and corresponding external variables were described in Supplementary Table 1.

Statistical analysis. To ensure the quality of our dataset, the "leave-one-out" meta-analysis by the "meta" packages was performed before conducting the meta-analysis (Supplementary Figure 3) and 15 published papers were excluded. We further quantified the effect size of NT on agricultural SOC storage in different soil layers at the global scale by weighting the Natural log-transformed response ratio with the inverse variance. Based on soil $\mathrm{C}$ saturation theory, equations of tending to an equilibrium value were selected to fit the relationship between the relative change rate of SOC storage and the experimental duration of NT. Boosted regression tree analysis was used to quantify the relative contribution of climate and soil properties on the relative change rate of SOC storage for all soil layers.

\section{References}

1. IPCC. Climate Change 2021: The Physical Science Basis. Contribution of Working Group I to the Sixth Assessment Report of the Intergovernmental Panel on Climate Change [Masson-Delmotte, V., P. Zhai, A. Pirani, S. L. Connors, C. Péan, S. Berger, N. Caud, Y. Chen, L. Goldfarb, M. I. Gomis, M. Huang, K. Leitzell, E. Lonnoy, J. B. R. Matthews, T. K. Maycock, T. Waterfield, O. Yelekçi, R. Yu and B. Zhou (eds.)]. Cambridge University Press. In Press. 2021.

2. Tubiello FN, Conchedda G. Emissions due to agriculture. Global, regional and country trends 19902018. FAO food and nutrition paper 1, (2021). https://www.fao.org/3/cb3808en/cb3808en.pdf.

3. Lal R. Soil carbon sequestration impacts on global climate change and food security. Science $\mathbf{3 0 4}$, 1623-1627 (2004).

4. Sanderman J, Hengl T, Fiske GJ. Soil carbon debt of 12,000 years of human land use. P. Natl. Acad. Sci. USA. 114, 9575-9580 (2017).

5. Phillips RE, Thomas GW, Blevins RL, Frye WW, Phillips SH. No-Tillage Agriculture. Science $\mathbf{2 0 8 , 1 1 0 8 -}$ 1113 (1980).

6. Kan ZR, et al. Mechanisms of soil organic carbon stability and its response to no-till: A global synthesis and perspective. Glob. Chang. Biol. (2021). https://doi.org/10.1111/gcb.15968.

7. Powlson DS, Stirling CM, Jat ML, Gerard BG, Palm CA, Sanchez PA, et al. Limited potential of no-till agriculture for climate change mitigation. Nat. Clim. Change 4, 678-683 (2014).

8. Cusser S, Bahlai C, Swinton SM, Robertson GP, Haddad NM. Long-term research avoids spurious and misleading trends in sustainability attributes of no-till. Glob. Chang. Biol. 26, 3715-3725 (2020). 
9. Yamanoshita M. IPCC Special Report on Climate Change and Land. Institute for Global Environmental Strategies (2019).

10. Lu F, et al. Soil carbon sequestrations by nitrogen fertilizer application, straw return and no-tillage in China's cropland. Glob. Chang. Biol. 15, 281-305 (2009).

11. Bai X, et al. Responses of soil carbon sequestration to climate-smart agriculture practices: A metaanalysis. Glob. Chang. Biol. 25, 2591-2606 (2015).

12. Cai $A$, et al. Changes in mineral-associated carbon and nitrogen by long-term fertilization and sequestration potential with various cropping across China dry croplands. Soil Till. Res. $205,15-25$ (2021).

13. Six J, Ogle SM, Jaybreidt F, Conant R, Mosier AR, Paustian K. The potential to mitigate global warming with no-tillage management is only realized when practised in the long term. Glob. Chang. Biol. 10, 155-160 (2004).

14. Martinez, Fuentes, JP, Silva, Valle, Acevedo. Soil physical properties and wheat root growth as affected by no-tillage and conventional tillage systems in a Mediterranean environment of Chile. Soil Till. Res. 99, 232-244 (2008).

15. Sun $\mathrm{W}$, et al. Climate drives global soil carbon sequestration and crop yield changes under conservation agriculture. Glob. Chang. Biol. 26, 3325-3335 (2020).

16. Pittelkow $\mathrm{CM}$, et al. Productivity limits and potentials of the principles of conservation agriculture. Nature 517, 365-368 (2015).

17. Zhao X, Liu SL, Pu C, Zhang XQ, Xue JF, Zhang R, et al. Methane and nitrous oxide emissions under no-till farming in China: a meta-analysis. Glob. Chang. Biol. 22, 1372-1384 (2016).

\section{Declarations}

\section{Data availability}

All data related to this manuscript are available from the Dryad Digital Repository: https://figshare.com/s/2ce3ca0f7446f9efc4d8.

\section{Acknowledgments}

Financial supports from the National Natural Science Foundation of China (42007073) is gratefully acknowledged. We thank all the researchers whose data were used in this global synthesis.

Author Contributions: Conceptualization, A.D., Y.E., J., and Y.C.; Data curation, A.D., T.J., and T.F.; Investigation, M.G. and P.S.; Methodology, A.D., and B.; Resources, A.D.; Supervision, P.S., A.D., and Y.E.; All authors contributed significantly to the writing of the manuscript.

\section{Competing financial interests}

The authors declare no competing interests. 
Figures

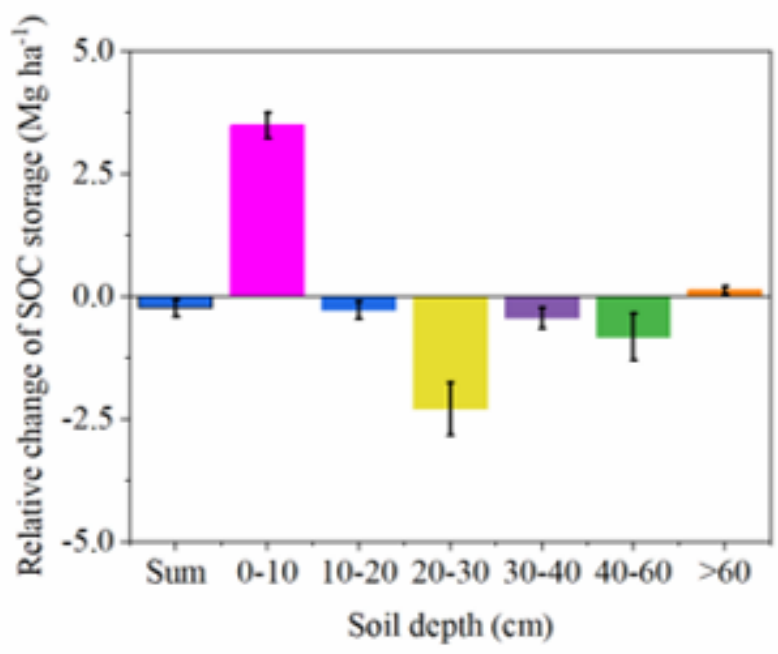

\section{Figure 1}

The relative change of SOC storage ( $\left.\mathrm{Mg} \mathrm{ha}^{-1}\right)$ under different soil depths when the trial of all duration is combined. Soil depth was divided into 6 layers: 0-10 cm (in magenta), $10-20 \mathrm{~cm}$ (in blue), 20-30 cm (in gold), $30-40 \mathrm{~cm}$ (in violet), $40-60 \mathrm{~cm}$ (in green), and $>60 \mathrm{~cm}$ (in brown). Sum refers to the sum of the relative change of SOC storage at all six depths. 


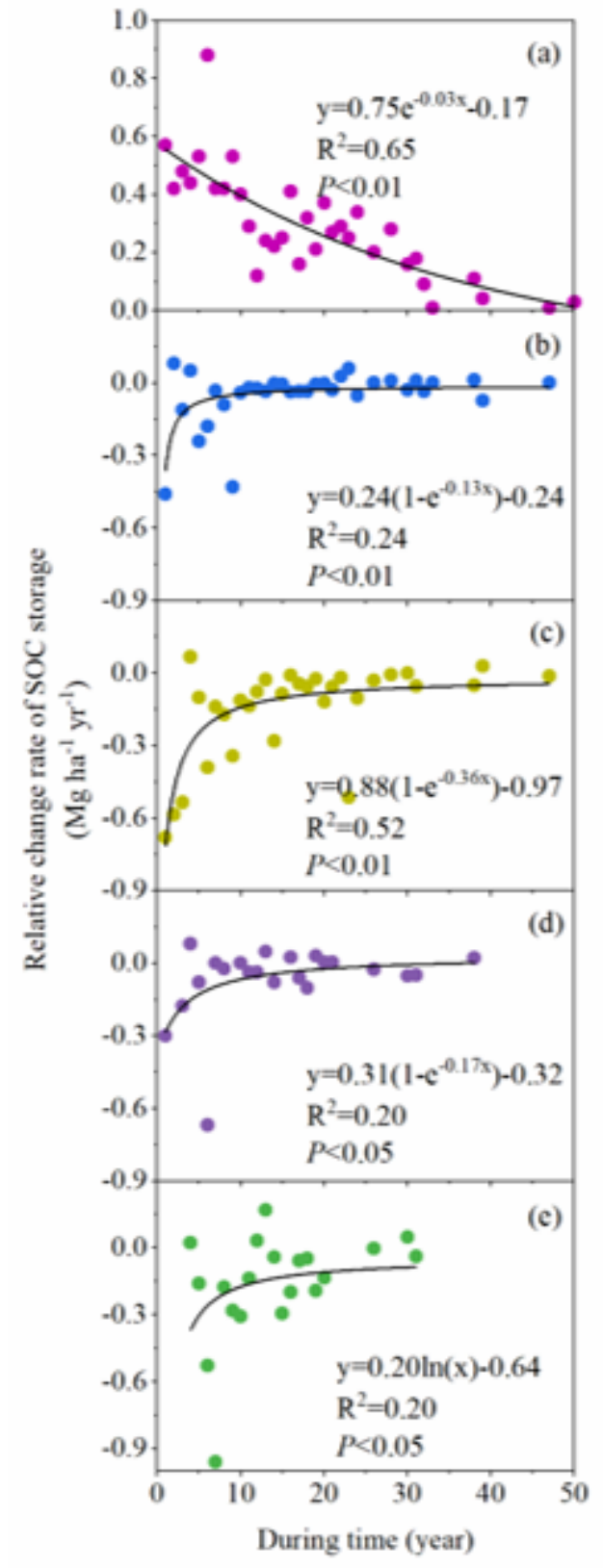

Figure 2

Relative change rate of soil organic carbon (SOC) storage ( $\left.\mathrm{Mg} \mathrm{ha}^{-1} \mathrm{yr}^{-1}\right)$ under no-tillage compared with conventional tillage as a function of time. $a, b, c, d, e$, and $\mathbf{f}$ represent the soil layers of $0-10 \mathrm{~cm}, 10-20 \mathrm{~cm}$, 20-30 cm, 30-40 cm, and 40-60 cm, respectively. Each solid point represents the average of the collected data for the corresponding year. 

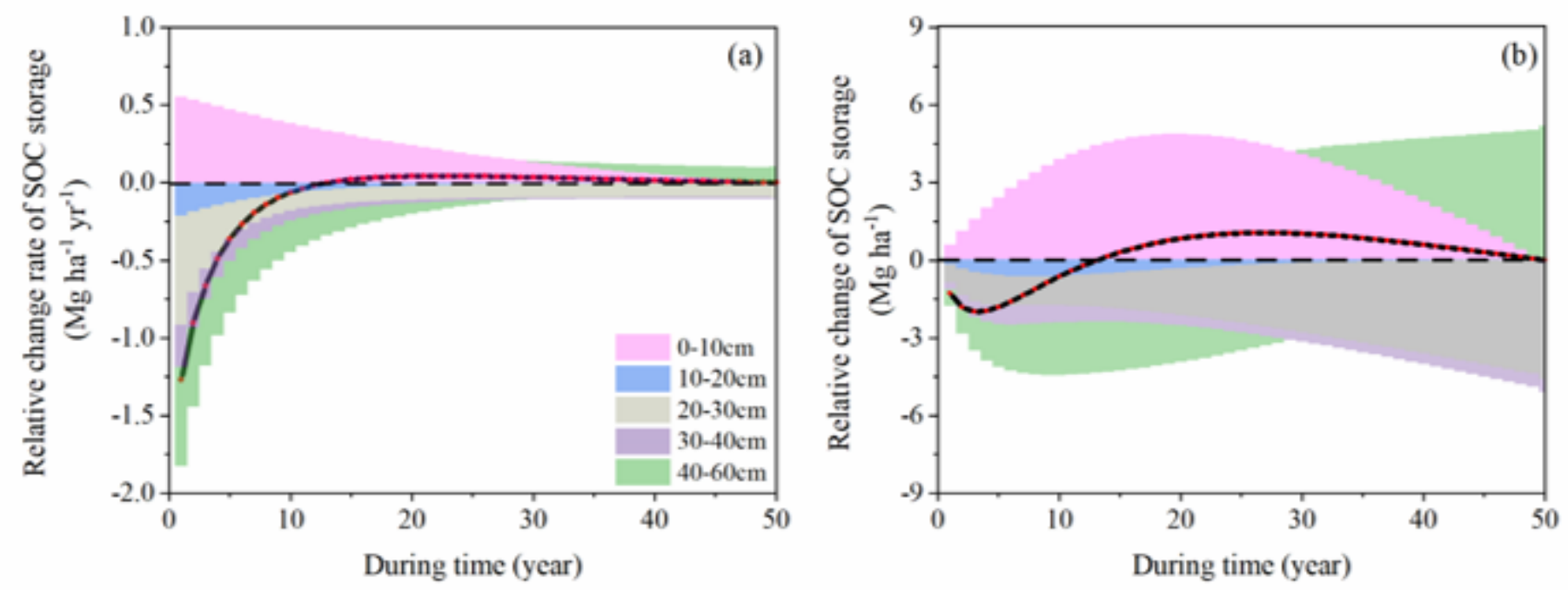

Figure 3

The effect of no-tillage on soil organic carbon (SOC) storage compared with conventional tillage. The size of the column represents the relative change rate of SOC storage (a) and the relative change of SOC storage (b) at the corresponding soil layers, which is calculated according to the equations in Figure 2. The solid dots in red are the average of the relative change rate of SOC storage and the relative change of SOC storage of all soil layers for each year.

\section{Supplementary Files}

This is a list of supplementary files associated with this preprint. Click to download.

- Supplementary.docx 